\title{
Severe Maternal Morbidity and Near Misses in Two Tertiary Referral Hospitals in Iran
}

\author{
Mahvash Zargar ${ }^{1, *} ;$ Javad Marfou ${ }^{1}$; Azam Afrakhteh ${ }^{1} ;$ Nahal Nasehi ${ }^{1}$ \\ ${ }^{1}$ Fertility, Infertility and Perinatology Research Center, Imam Khomeini Hospital, Ahvaz Jundishapur University of Medical Sciences, Ahvaz, IR Iran \\ ${ }^{*}$ Corresponding author: Mahvash Zargar, Fertility, Infertility and Perinatology Research Center, Imam Khomeini Hospital, Ahvaz Jundishapur University of Medical Sciences, Ahvaz, \\ IR Iran. Tel: +98-9161188199, E-mail: dr.zargar118@yahoo.com
}

Received: December 7, 2014; Accepted: March 12, 2015

\begin{abstract}
Background: Investigating severe maternal morbidity/near miss is a newly recognized tool which identifies women at the highest risk of maternal death and helps allocate resources, especially in developing countries.

Objectives: This study aimed to document the prevalence and causes of severe maternal morbidity (SMM) at two educational hospitals in Ahvaz, Khuzestan, Iran.

Patients and Methods: In this prospective study, we found and selected SMM patients based on organ failure criteria from patients admitted in two educational hospitals of Ahvaz Jundishapur University of Medical Sciences during 2009-2010. Until recovery discharge or death, the diagnosis and management of these patients were under observation of obstetricians. The main outcome was maternal mortality ratio, SMM rate (SMMR).

Results: Totally, there were 12,149 deliveries, eight maternal deaths and 226 SMM cases. This study showed the SMMR of 18.6/1000 live births, an MMR of 65.8/100000 live births, and case fatality ratio of $1 / 28$ or 3.5\%. Severe preeclampsia and hemolysis elevated liver enzymes low platelet count syndrome (HELLP) (38\%), hemorrhage (23\%) and ectopic pregnancy (14\%) were the top causes of SMM. Similar to HELLP syndrome (25\%) hemorrhage (25\%), sepsis (25\%) was the commonest cause of mortality; $39 \%$ of patients were referred from primary or secondary health care units; $85 \%$ of the cases needed intensive care unit admissions.

Conclusions: SMM analysis provides valuable information on obstetric care. This study highlighted the need to improve antenatal care, which would help early identification of high-risk pregnancies. Every SMM could progress to maternal mortality if is not suspected, diagnosed and managed on its golden time.
\end{abstract}

Keywords: Morbidity; Maternal Mortality; Live Births

\section{Background}

World Health Organization (WHO) estimated that there were 287000 maternal deaths worldwide in 2010. Of all the deaths, 95\% occurred in developing countries (1), revealing major political, economic and social differences between countries and regional differences, especially regarding women's health. According to WHO, the estimated maternal mortality ratio (MMR) in Iran in 2010 was 21 per 100,000 live births. Sistan and Baluchestan and Khorasan provinces were the regions in Iran with the highest MMRs, while direct obstetric causes account for $49 \%$ of maternal deaths and the main causes are hypertensive diseases, followed by hemorrhage and puerperal infections and pulmonary embolism (2). Maternal death is used as a parameter to assess the quality of health services by identifying the situations of inequality and contributing to the assessment of levels of health and socioeconomic development of a population (2). Maternal deaths are the tip of the iceberg of maternal disability and for every woman who dies many more will survive, but often have lifelong disabilities $(2,3)$. Severe maternal morbidity or near miss is a newly described condition which has been investigated for 20 years. Near misses are defined as pregnant women with severe life-threatening conditions who nearly die during pregnancy, childbirth or the postpartum period; but with good luck or good care, they survive. A near miss case is a woman with at least one near miss event (4-7). Severe maternal morbidity or near miss can be a more valuable indicator in analyzing the obstetric care than maternal mortality, as this condition has greater incidence rates and offers a good opportunity for data collection, as the woman herself can be a source of information. Therefore, the study of severe maternal morbidity or near miss is a key to advanced knowledge about risk factors during pregnancy and it can be a valuable tool for monitoring the delivery of obstetrical care $(5,8)$. Once maternal morbidity precedes maternal death, the systematic identification and the study of near miss cases help in further understanding of the determinants of maternal mortality. Unlike developed countries, in Iran there is limited experience with the use of near miss reviews as a tool for monitoring the quality of maternity services in developing countries. There are now a

Copyright (C) 2015, Ahvaz Jundishapur University of Medical Sciences. This is an open-access article distributed under the terms of the Creative Commons Attribution-NonCommercial 4.0 International License (http://creativecommons.org/licenses/by-nc/4.0/) which permits copy and redistribute the material just in noncommercial usages, provided the original work is properly cited. 
number of statistical data systems that measure indicators of unplanned events caused by errors that had potential to injure patients. Most studies have used Mantel (9) and Waterstone (10) classifications as they have been published prior to the proposed WHO classification (11). The criteria for diagnosis of maternal near miss have been standardized. Three approaches based on different indicators have been proposed to identify severe maternal morbidity/near miss: 1) organ dysfunction (9); 2 ) presence of conditions or complications $(10,12)$ such as preeclampsia, uterine rupture or severe sepsis; and 3) the level of care complexity such as blood transfusion or intensive care unit (ICU) admission $(13,14)$. The WHO Working Group on Maternal Mortality and Morbidity has recently developed a uniform set of criteria for case identification based on three established approaches with clinical, laboratory and management markers (11). This event is most commonly known as "severe maternal morbidity," "severe acute maternal morbidity" or "near miss". WHO (11) argues that "maternal near miss" is the term that better reflects the notion of "nearly dying but surviving" and recommends its use. The present study aimed to describe the epidemiological profile of severe maternal morbidity/near miss and its maternal characteristics and perinatal outcomes in two referral maternity hospitals. This study was conducted to determine the prevalence of near miss cases and the nature of near miss events and mortalities among the obstetric patients to serve as a complementary method for auditing the quality of maternal health care in our institution. Because maternal deaths have become so uncommon, the practice of analyzing severe maternal morbidity evolved as a surrogate to improve obstetrical and perinatal care. Because avoidance of medical errors serves to decrease the risks for maternal mortality or severe maternal morbidity, the concept of near misses or close calls was also introduced.

\section{Patients and Methods}

A cross-sectional study was conducted at the Razi and Emam Khomeini hospitals in Ahvaz, Iran, during 2009 - 2010. These hospitals include a maternity ward and a surgery center, an adult ICU, a neonatal ICU (NICU), and a blood bank. Teams of obstetricians, anesthesiologist, neonatologists and intensive care specialists are available round the clock. Emam Khomeini and Razi, the two educational hospitals of Ahvaz Jundishapur University of Medical Sciences, are tertiary referral hospitals that provide care to high-risk pregnant women in Khuzestan Province with an estimated population of 4,274,979 inhabitants in 2009. The study included women who showed any clinical signs during pregnancy, childbirth or within the first 42 days postpartum who met the defining criteria of severe maternal morbidity/near miss based on the WHO classification (Table1)(11). Data was collected from 2009 to 2010 by the principal investigator of Ahvaz Jundishapur University Medical Sciences. Suspected cases of severe ma- ternal morbidity/near miss were identified during daily visits to the ICU and obstetrics ward and review of hospital admissions records. Once they were identified, the patients were followed up by reviewing medical, nursing and blood bank records as well as the death certificates from the hospital administrative department to rule out or confirm suspected cases of severe maternal morbidity/ near miss. Data of the confirmed cases were entered into a data collection form without direct contact or interview with the women. The data collection instrument was based on the WHO criteria. After case confirmation, consistency and completeness of the data were evaluated and then they were entered into a database using Microsoft SPSS Excel 2003. The main outcomes were maternal mortality ratios and Severe Maternal Morbidity (SMM) rate. The following variables were collected: age; gestational age, gravidity, parity; type of delivery; perinatal data.

\section{Results}

During the 12 months of the study, 12149 women were admitted to Emam Khomeini and Razi hospitals for childbirth. There were eight maternal deaths from obstetric causes with an MMR of 65.8 per 100000 live births. The 226 women with severe maternal morbidity/near miss were diagnosed based on WHO criteria. The severe maternal morbidity/near miss rate was 18.6 per 1000 live births (Table 2) (11). The characteristics of the women diagnosed with severe maternal morbidity/near miss are presented in (Table 3). Their mean age was 27.8 years old; the mean gestational age was 31 weeks. We found a high cesarean rate $(85 \%)$ because of the severity of these patients' obstetric conditions. Their pregnancies usually required urgent actions. Cesarean is associated with high rates of maternal morbidity and mortality. The outcomes of pregnancy were 153 live births, 41 stillbirths, and 32 ectopic pregnancies. The mean weight of the newborn was 2113 g; $9 \%$ of the newborns had intrauterine growth restriction (IUGR), $12.6 \%$ had fetal distress due to the meconium passage and abruption. The causes of SMM are presented in Table 4. The most common causes of SMM were severe preeclampsia, hemolysis elevated liver enzymes low platelet count syndrome (HELLP) (38\%) and hemorrhage (23\%). Other causes were eclampsia (9\%), cardiac disease (3.5\%), sickle cell anemia (3.5\%), cholestasis (2\%), acute fatty liver (1.5\%), sepsis (1.5\%), high spinal block (1\%), pulmonary embolism, acute renal failure, sub-arachnoid hemorrhage DVT, bladder rupture, scleroderma, H1A1 influenza, and thyroid storm (3\%). The cause of maternal death are present in Table 5 that including: DIC (Disseminated intravascular coagulation) and atonia (2 cases), HELLP syndrome (2 cases), sepsis (2 cases), Scleroderma (1 case), Sickle cell anemia (1 case). Comparison of near miss events and primary cause of maternal death is present in Table 6. As for the clinical outcome, 214 women were discharged in good health, eight were with sequelae, and 14 were transferred to other wards. 
Zargar M et al.

Table 1. Diagnostic Criteria of Severe Maternal Morbidity According to World Health Organization ${ }^{\mathrm{a}}$

\section{WHO Criteria}

\begin{tabular}{|c|c|c|c|}
\hline Clinical Criteria & Laboratory Criteria & Management Criteria & Dysfunction \\
\hline $\begin{array}{l}\text { Gasping; acute cyanosis; respi- } \\
\text { ratory frequency }>40 \text { or }<6 \text {; } \\
\text { pulmonary edema }\end{array}$ & Oxygen saturation $<90 \%$ for $\geq 60$ & $\begin{array}{c}\text { Intubation and ventilation } \\
\text { for } \geq 60 \text { minutes, not related } \\
\text { to anesthesia }\end{array}$ & Respiratory dysfunction \\
\hline $\begin{array}{l}\text { Shock; unconsciousness and } \\
\text { no pulse/heartbeat; } \mathrm{BP}=170 / 110 \\
\text { mmHg twice, } 6 \text {-hours apart }\end{array}$ & Lactate $>5 ; \mathrm{pH}<7.1$ & $\begin{array}{l}\text { Cardiopulmonary resuscita- } \\
\text { tion }\end{array}$ & $\begin{array}{l}\text { Cardiovascular dysfunc- } \\
\text { tion }\end{array}$ \\
\hline
\end{tabular}

mmHg twice, 6-hours apart

or; cardiac failure or arrest;

systolic BP $<90 \mathrm{mmHg}$; Free

fluid infusion

\begin{abstract}
Oliguria not responsive to
fluids or diuretics; diuresis less

than $400 \mathrm{~mL} / 24$ hours, refrac-

tory to hydration, furosemide

or dopamine; rupture of blad-

der post-surgery
\end{abstract}

Jaundice with pre-eclampsia; acute fatty liver

\section{Coagulation disorders Acute thrombocytopenia requiring platelet transfusion; sickle cell anemia}

Hemorrhage due to placenta pathology; Uterine rupture

\section{Creatinine $\geq 300 \mathrm{mmol} / \mathrm{L}$ or $\geq 3.5$ Dialysis for acute renal failure}

Renal dysfunction
Bilirubin $>100 \mathrm{mmol} / \mathrm{L}$ or $>6.0$ $\mathrm{mg} / \mathrm{dL}$; LFT dysfunction
Hepatic dysfunction

Transfusion $\geq 4 \mathrm{U}$ pc or RBC; Coagulation/hematologitransfusion platelets cal dysfunction
Total paralysis; stroke; eclampsia; subarachnoid or intraparenchymal hemorrhage; total paralysis; loss of consciousness for $\geq 12 \mathrm{~h}$; status epilepsy

\section{Septic shock}

Severe hypotension after-

blockade and intubation; $\mathrm{BP}<$ $90 \mathrm{mmHg}$ for $\geq 1 \mathrm{~h}$
Diabetic ketoacidosis; thyroid storm

\section{Hysterectomy for postpar-}

tum; laparotomy due to ectopic pregnancy or hemorrhagic cyst
Uterine dysfunction$$
\text { (n) }
$$

Neurological dysfunc-
tions

a Abbreviations: BP, blood pressure; PRBCs, packed red blood cells; ICU, intensive care unit.

Table 2. Indicators Proposed by World Health Organization for Maternal Near Miss, According to the Criteria

\begin{tabular}{|c|c|}
\hline WHO Indicators & $\mathrm{WHO}^{\mathrm{a}}$ \\
\hline $\begin{array}{l}\text { Absolute number of near } \\
\text { miss cases }\end{array}$ & 226 \\
\hline Near miss rate ${ }^{c}$ & 18.6/1000 live birth \\
\hline $\begin{array}{l}\text { Maternal near miss/mor- } \\
\text { tality ratio } d\end{array}$ & $226 / 8$ \\
\hline Maternal mortality rate ${ }^{e}$ & $65.8 / 100000$ live birth \\
\hline \multicolumn{2}{|c|}{$\begin{array}{l}\text { a } \text { Abbreviation: WHO; World Health organization. } \\
{ }^{b} \text { Absolute number of near miss cases. } \\
{ }^{c} \text { The incidence of near miss cases refers to the number of maternal } \\
\text { near misses by } 1000 \text { live births. } \\
d_{\text {Maternal near miss/mortality ratio-ration between cases of maternal }} \\
\text { near miss and maternal deaths. } \\
\mathrm{e}_{\text {Mortality rate, number of maternal deaths by the number of women }} \\
\text { in life-threatening situations (\%). }\end{array}$} \\
\hline
\end{tabular}

\begin{tabular}{lc}
\hline \multicolumn{2}{l}{ Table 3. Characteristic of Maternal Near Miss Cases ${ }^{\mathrm{a}}$} \\
\hline Characteristics & Maternal Near Miss $(\mathbf{n}=\mathbf{1 9 8})$ \\
\hline Mean age, $\mathbf{y}$ & 27.8 \\
\hline Mean gestational age, wk & 31 \\
\hline Parity, median & 1 \\
\hline Gravidity, median & 2 \\
\hline IUGR $^{\text {b }}$ & $16(9)$ \\
\hline IUFD $^{\text {b }}$ & $41(18)$ \\
Meconium passage $^{\text {b }}$ & $8(4.6)$ \\
$\begin{array}{l}\text { Weight of newborn, } \\
\text { mean, } \mathbf{g}\end{array}$ & 2113 \\
Abruption & \\
\hline
\end{tabular}

\footnotetext{
a Abbreviations: IUGR, intrauterine growth restriction; IUFD, intrauterine fetal death.

$\mathrm{b}$ Values are presented as No. (\%)
} 
Table 4. Nature of Near Miss Events ${ }^{a}$

\begin{tabular}{lc}
\hline Write Expended form & Frequency, No. (\%) \\
\hline $\begin{array}{l}\text { Severe preeclampsia, HELLP } \\
\text { syndrome }\end{array}$ & $86(38)$ \\
\hline Obstetric hemorrhage & $53(23)$ \\
\hline \multicolumn{1}{|l}{ Placenta previa } & $23(10)$ \\
\hline Placental abruption, DIC & $9(4)$ \\
\hline Uterine rupture & $9(4)$ \\
\hline Uterine atony & $8(3)$ \\
\hline Damage of obstetric canal & $4(2)$ \\
\hline Ectopic pregnancy & $32(14)$ \\
\hline Eclampsia & $20(9)$ \\
\hline Cardiac disease & $8(3.5)$ \\
\hline Sickle cell anemia & $8(3.5)$ \\
\hline Cholestasis & $4(2)$ \\
\hline Acute fatty liver of pregnancy & $3(1.5)$ \\
\hline Sepsis & $3(1.5)$ \\
\hline High spinal block & $2(1)$ \\
\hline Others & $7(3)$ \\
\hline Pulmonary embolism & 1 \\
\hline Acute renal failure & 1 \\
\hline Sub-arachnoid hemorrhage & 1 \\
\hline DVT, bladder rupture & 1 \\
\hline Scleroderma & 1 \\
\hline H1A1 influenza & $100)$ \\
\hline Thyroid storm & 1 \\
\hline Abbreviations: DIC, Disseminated intravascular coagulation; DVT, \\
\hline
\end{tabular}

Table 5. Nature of Maternal Deaths Events ${ }^{a}$

\begin{tabular}{lc}
\hline Diagnosis & Frequency, No. \\
\hline DIC, atony & 2 \\
HELLP syndrome & 2 \\
\hline Sepsis & 2 \\
Scleroderma & 1 \\
Sickle cell anemia & 1 \\
\hline Total & 8 \\
\hline
\end{tabular}

${ }^{a}$ Abbreviations: DIC, Disseminated intravascular coagulation; HELLP, Hemolysis elevated liver enzymes low platelet count.
Table 6. Comparison of Near Miss Events and Primary Causes of Maternal Deaths ${ }^{\text {a }}$

\begin{tabular}{lcc}
\hline Diagnosis & Near Miss & Mortality \\
\hline $\begin{array}{l}\text { Hypertensive disorders of } \\
\text { pregnancy }\end{array}$ & 106 & 2 \\
\hline Severe hemorrhage & 85 & 2 \\
\hline Sepsis & 3 & 2 \\
\hline Scleroderma & 1 & 1 \\
\hline Cardiac & 8 & 0 \\
\hline Anesthetic complication & 2 & 0 \\
\hline Sickle cell anemia & 8 & 1 \\
\hline Others & 13 & 0 \\
\hline Total & 226 & 8 \\
\hline
\end{tabular}

a Abbreviations: HELLP, Hemolysis elevated liver enzymes low platelet count; PPH, postpartum hemorrhage.

\section{Discussion}

So far, no provincial statistics on severe maternal morbidity has been officially published in Iran. In 2009, the population of Khuzestan province was 4,274,979 and this province was the sixth in the country, constituting $6.2 \%$ of the total population of Iran. According to the figures published, Khuzestan province is at the third place in terms of birth after Tehran and Khorasan Razavi provinces. Therefore, efforts to reduce maternal death in this province can be a high step to reduce maternal mortality in the country. In the two educational hospitals, Razi and Imam Khomeini in Ahvaz city, which are the main locations of the Gynecology Department of Ahvaz Jundishapur University of Medical Sciences, at the time of the study, about 12,149 childbirths occurred, which was about $11.7 \%$ of the total birth of the province. A high percentage of patients (39\%) in the study had been referred from other centers, and as a result, the overall prevalence of SMM in these two hospitals was higher than the actual statistics of the whole province. The prevalence of SMM morbidity in this study was 18.6 per 1000 deliveries. Of every 100 pregnant women, 2 (1.86) were exposed to extreme levels of SMM (case fatality ratio $=3.5 \%$ ). The statistics obtained from this study were not comparable to the ones form developed countries, but were in the range announced by WHO (15) and were close to those of other developing countries. Among the few countries in Middle East, the statistical reports available from this study are acceptable. It seems that the situation in Iran is now better than other countries of the region. In terms of maternal mortality statistics, after the Turkey, Iran has the lowest statistics of death in the Middle East (16). In this study, the number of maternal deaths was 23 , of which, eight cases had happened in these two hospitals; $34.7 \%$ of the total deaths in the province were related to these two hospitals. The most important justification for this high figure can be the lack of features in 
other centers and the fact that they are referral centers. Of eight deaths occurred, two cases had been referred to this hospital in the final stages and each was hospitalized in these centers just as few as a couple of hours; therefore, they can be removed from the death statistics; thus, 26\% of all the maternal deaths in the province belonged to the two hospitals (case fatality ratio $=2.6 \%$ ). In this study, he two main causes of death of mothers, similar to other developing countries, were bleeding and hypertension, which unfortunately were mostly preventable. Sepsis was also the third leading cause of death of mothers and according to its high prevalence, it should be taken into consideration. The most common causes of SMM in this study were preeclampsia and HELLP syndrome of delivery hemorrhages which was consistent with the effects of maternal mortality. Brazilian studies (17-20) also reported hypertensive syndromes as the most commonly associated causes with severe maternal morbidity/near miss, as high as 57\% in Souza et al. study (17). Adisasmita et al. (21) in Indonesia also found that $57.3 \%$ of women had hypertension syndrome as a primary cause of maternal near miss. Reichenheim et al. (22) reviewed the literature for indicators of near miss and found ICU admission (54.9\%), eclampsia and obstetric hemorrhage (52.9\%) as the most commonly identified causes. Filippi et al.(23) in a study in Africa identified hemorrhage and hypertensive disorders of pregnancy as the most common conditions associated with near miss. In studies in other areas, the prevalence and criteria of SMM are different and numerous.

The Mantel (9) and WHO (11) classification were able to identify a comparatively similar proportion of cases. These criteria, especially the WHO (11) classification, showed a very high threshold for the detection of cases of maternal near miss, missing a significant proportion of women with highly relevant conditions such as preeclampsia and eclampsia.

For example, in 2004, the SMM statistics reported from other parts of the world and announced the prevalence of SMM between $0.07-8.23 \%$, with a case fatality ratio $=0.02-37 \%$. In a study in Nigeria from June 2002 to December 2004, the SMM reported was 140/1000 live births and the maternal mortality rate was 2931/100 000 (11). In this study, the most common causes of maternal death and SMM were blood pressure and bleeding (24). In a cross-sectional study in Bolivia, severe maternal morbidity/ near miss was 50/1000 live births and the maternal mortality rate was 187/100000 living births. In this study, the most common causes of maternal death and severe maternal morbidity/near miss were blood pressure and bleeding (25). In a study in the University Hospital of Fatima in Karachi, Pakistan, the prevalence of severe maternal morbidity/near miss was 32.9/1000 and the causes of severe maternal morbidity/near miss was bleeding anemia dystocia (26). In a study at the University of Damascus, Syria, the prevalence of severe maternal morbidity/ near miss was 32.9/1000. In this study, the most common causes of maternal death and SMM were blood pressure and bleeding, too (27). In addition, among developed countries, in a report from the UK in 2002, hospitalization in the ICU was considered as an SMM index. The prevalence of SMM was $<0.1 \%$ with a case fatality ratio $<6 \%$. Informal studies conducted in the United States reported about 50 intense morbidities versus one case of maternal death, i.e., five out of every 1000 deliveries. In other developed countries, statistics show about 5 - 8 cases per 1000 deliveries (28), that of course, statistics of countries like Iran still have a large distance with these countries' statistics.

Timely detection of cases with the severe maternal morbidity is the first step in preventing the death of the mother. In the next stage, according to the capabilities and equipments, necessary measures should be done for treatment or referral of the patient. Especially it is important in cases where that disease's nature in a type of sickle cell anemia, HELLP syndrome, sepsis that results in high mortality, like a patient's. Timely referral to centers level 3 that have appropriate therapeutic and diagnostic equipments, intensive care unit (ICU) and medical team, consisting of various specialties.

Finally it seems that the existence of the specific charge to follow up the diagnostic measures and create harmony between different groups, plays an effective role in preventing a transform in the severe maternal morbidity to maternal death cases.

\subsection{Conclusions}

Severe maternal morbidity/near miss analysis provides valuable information on obstetric care. The occurrence of complications during pregnancy is not only associated with the level of human development, but also with differences in detection and management of obstetric complications. Prompt diagnosis and adequate management contribute to differences in maternal morbidity and mortality rates between countries and regions. This study highlighted the need to improve antenatal care, which would help early identification of high-risk pregnancies. Every severe maternal morbidity/near miss could progress to maternal mortality if is not suspected, diagnosed and managed on its golden time.

\section{Funding/Support}

This research was supported by the Department of Gynecology, Ahvaz Jundishapur University of Medical Sciences.

\section{References}

1. world health statistics.. World health statistics.: WHO; 2009. Available from: http://www.who.int/whosis/whostat/2009/en.

2. National Maternal Mortality Study. Ministry of Health editor. Egypt; 1992-1993.

3. Oona C, Reginald G, Adel H, Nahed M, Bothina E. National maternal mortality ratio in Egypt halved between 1992-93 and 2000.Egypt: Bulletin of the World Health Organization; 2005.

4. Stones W, Lim W, Al-Azzawi F, Kelly M. An investigation of mater- 
nal morbidity with identification of life-threatening 'near miss' episodes. Health Trends. 1991;23(1):13-5.

5. Souza JP, Cecatti JG, Parpinelli MA, de Sousa MH, Serruya SJ. [Systematic review of near miss maternal morbidity]. Cad Saude Publica. 2006;22(2):255-64.

6. Ronsmans CVF. Reviewing maternal deaths and complications to make pregnancy safer.Geneva: World Health Organization; 2004.

7. Pattinson RC, Hall M. Near misses: a useful adjunct to maternal death enquiries. Br Med Bull. 2003;67:231-43.

8. Amaral E, Luz AG, Souza JPD. A morbidade materna grave na qualificacao da assistencia: utopia ou necessidade? Braz J Obstet Gynecol .2007;29(9).

9. Mantel GD, Buchmann E, Rees H, Pattinson RC. Severe acute maternal morbidity: a pilot study of a definition for a near-miss. $\mathrm{Br} J$ Obstet Gynaecol.1998;105(9):985-90.

10. Waterstone M, Bewley S, Wolfe C. Incidence and predictors of severe obstetric morbidity: case-control study. BMJ. 2001;322(7294):1089-93.

11. Pattinson R, Say L, Souza JP, Broek N, Rooney C, W. H. O. Working Group on Maternal Mortality, et al. WHO maternal death and near-miss classifications. Bull World Health Organ. 2009;87(10):734.

12. Prual A, Bouvier-Colle MH, de Bernis L, Breart G. Severe maternal morbidity from direct obstetric causes in West Africa: incidence and case fatality rates. Bull World Health Organ. 2000;78(5):593602.

13. Baskett TF, Sternadel J. Maternal intensive care and near-miss mortality in obstetrics. BrJ Obstet Gynaecol. 1998;105(9):981-4.

14. Dias de Souza JP, Duarte G, Basile-Filho A. Near-miss maternal mortality in developing countries. Eur J Obstet Gynecol Reprod Biol. 2002;104(1):80.

15. Say L, Pattinson RC, Gülmezoglu AM. WHO systematic review of maternal morbidity and mortality: the prevalence of severe acute maternal morbidity (near miss). Reprod Health. 2004;1(1):3.

16. World Health Organization.. Trends in maternal mortality WHO Library Cataloguing in publication Data 1990-2008. 2010. Available from: http://www.unfpa.org/sites/default/files/pub-pdf/trends_ matmortality90-08.pdf.
17. Souza JP, Cecatti JG, Parpinelli MA, Serruya SJ, Amaral E. Appropriate criteria for identification of near-miss maternal morbidity in tertiary care facilities: a cross sectional study. BMC Pregnancy Childbirth. 2007;7:20.

18. de Souza JP, Cecatti JG. The near-miss maternal morbidity scoring system was tested in a clinical setting in Brazil. J Clin Epidemiol. 2005;58(9):962.

19. Luz AG, Tiago DB, Silva JC, Amaral E. [Severe maternal morbidity at a local reference university hospital in Campinas, Sao Paulo, Brazil]. Rev Bras Ginecol Obstet. 2008;30(6):281-6.

20. Amorim MM, Katz L, Valenca M, Araujo DE. [Severe maternal morbidity in an obstetric ICU in Recife, Northeast of Brasil]. Rev Assoc Med Bras. 2008;54(3):261-6.

21. Adisasmita A, Deviany PE, Nandiaty F, Stanton C, Ronsmans C. Obstetric near miss and deaths in public and private hospitals in Indonesia. BMC Pregnancy Childbirth. 2008;8:10.

22. Reichenheim ME, Zylbersztajn F, Moraes CL, Lobato G. Severe acute obstetric morbidity (near-miss): a review of the relative use of its diagnostic indicators. Arch Gynecol Obstet. 2009;280(3):33743.

23. Filippi V, Ronsmans C, Gohou V, Goufodji S, Lardi M, Sahel A, et al. Maternity wards or emergency obstetric rooms? Incidence of near-miss events in African hospitals. Acta Obstet Gynecol Scand. 2005;84(1):11-6.

24. Oladapo OT, Sule-Odu AO, Olatunji AO, Daniel OJ. "Near-miss" obstetric events and maternal deaths in Sagamu, Nigeria: a retrospective study. Reprod Health. 2005;2:9.

25. Roost M, Altamirano VC, Liljestrand J, Essen B. Priorities in emer gency obstetric care in Bolivia--maternal mortality and nearmiss morbidity in metropolitan La Paz. BJOG. 2009;116(9):1210-7.

26. Mustafa R, Hashmi H. Near-miss obstetrical events and maternal deaths.J Coll Physicians Surg Pak. 2009;19(12):781-5.

27. Almerie Y, Almerie MQ, Matar HE, Shahrour Y, Al Chamat AA, Abdulsalam A. Obstetric near-miss and maternal mortality in maternity university hospital, Damascus, Syria: a retrospective study. BMC Pregnancy Childbirth. 2010;10:65.

28. Cunningham F, Leveno K, Bloom S, Hauth J, Rouse D, Spong C. Williams obstetrics.New Yourk: MC Graw Hill; 2010. 